\title{
The Influence of Culture and Leadership on Cost Estimation
}

\author{
Khaled Hamdan ${ }^{1}$, Boumediene Belkhouche ${ }^{2}$, and Peter Smith ${ }^{3}$ \\ ${ }^{1}$ UAE University, Al Ain, UAE \\ khamdan@uaeu.ac.ae \\ 2 CIT, UAE University, Al Ain, UAE \\ b.belkhouche@uaeu.ac.ae \\ ${ }^{3}$ University of Sunderland, Sunderland, UK \\ peter.smith@sunderland.co.uk
}

\begin{abstract}
Culture and leadership factors play an important role in software development and cost estimation. We discuss the many dimensions of culture and leadership and their impact on cost estimation in software development. We conducted a survey to identify leadership and cultural factors that may influence the software development process and its associated cost. A cost estimation model incorporating these factors was developed and evaluated.
\end{abstract}

Keywords: Effort estimation, Leadership, Team culture, CBR, Ontology.

\section{Introduction}

Culture and leadership impact significantly the operation of an organization [1]. The quality of the software team (i.e., capabilities of the project manager, the programmers and the analysts) is a major factor in determining the cost and quality of software products [2]. The values of the leader(s) and individual awareness of the culture of the organization are determining factors in the organization productivity. Organizational culture incorporates a set of assumptions, beliefs, and values, which guide the organization members' functions. Culture is one of the most important aspects that affect peoples' lives, their behaviours and their thinking. Culture is not an easy concept to define. It "has been aptly compared to an iceberg. Just as an iceberg has a visible section above the waterline, and a larger, invisible section below the water line, so culture has some aspects that are observable and others that can only be suspected, imagined, or intu-ited. Also like an iceberg, that part of culture that is visible (observable behaviour) is only a small part of a much bigger whole" [3]. Researchers have repeatedly shown that the lack of leadership support within a project is often a cause of the project ultimate failure [4]. The leader of an organization has an essential role to play in setting the vision that the organization should embrace to move towards.

The main hypothesis of our research is that organizational culture and project leadership are significant contributing factors in the cost of software development. For our study, we selected the Arabian Gulf States [5]. In order to test 
this hypothesis, a survey of software development projects within government departments in the United Arab Emirates (UAE) was undertaken. The analysis of the survey highlighted several parameters affecting cost estimation in this area. Based on this analysis, new projects were monitored to ascertain the impact of organizational culture and leadership on software effort estimation. Our ultimate goal was to develop a CBR-based cost estimation model that incorporates leadership and culture (Fig. (1) [], [7], [].

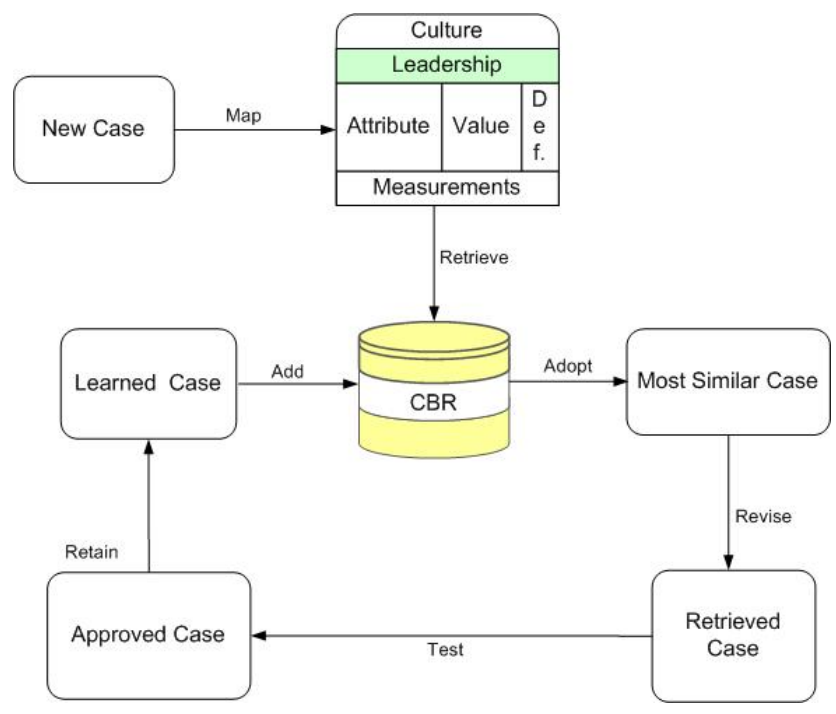

Fig. 1. The Augmented CBR

\section{Leadership and Culture Parameters}

Numerous models for measuring and estimating software development efforts have been proposed 1, 4. These models have not focused on cultural issues within organizations or leadership characteristics of project managers. In an effort to derive an improved cost estimation model that is sensitive to local customs, we used a survey to identify which parameters impact the cost estimation model development. The identified parameters are categorized into seven groups (Fig. 21): Organization Line of Business, Application Type, Organization Type, Organization Culture, Project Leadership, Project Technical Environment and Year of Project Completion.

While studying these parameters we defined a Case-Based modelling process as shown in Fig. 3 This process identifies the stages to follow and the parameters that should be taken into consideration when performing software effort estimation. This process was also used in the development of the implemented system. 


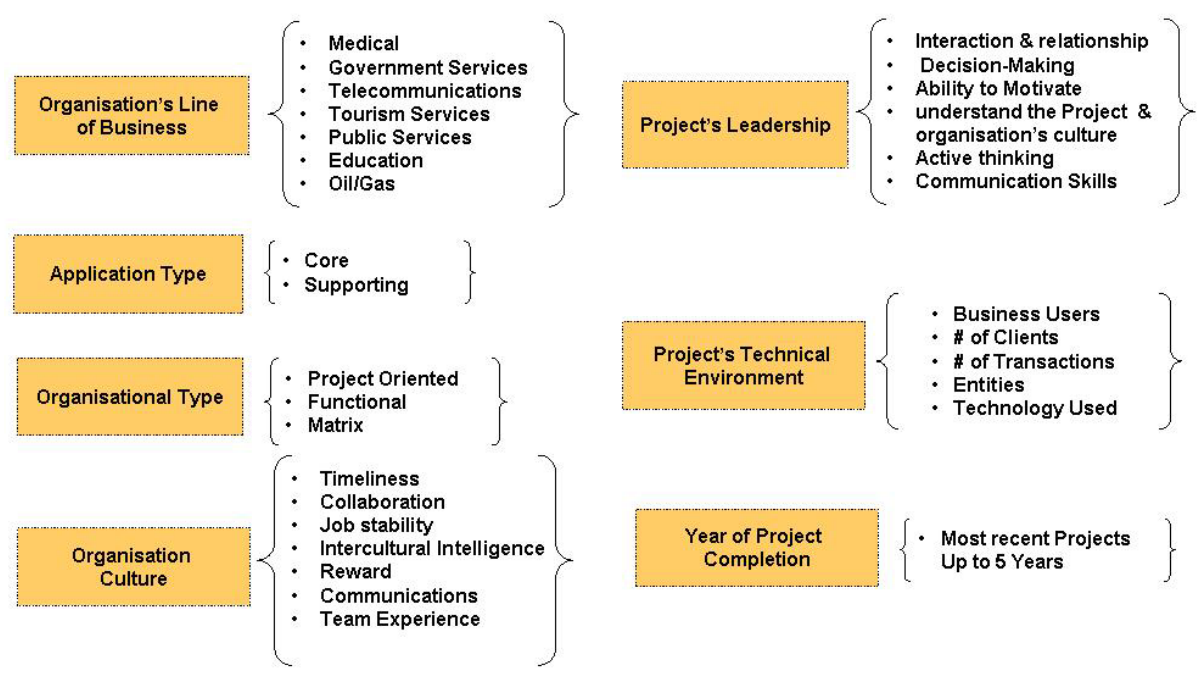

Fig. 2. Parameter Groups

\begin{tabular}{|c|c|c|c|c|c|c|}
\hline $\begin{array}{c}\text { Deternine } \\
\text { Onganisation's } \\
\text { line of } \\
\text { Business }\end{array}$ & $\begin{array}{l}\text { Detemine the } \\
\text { Application } \\
\text { Type }\end{array}$ & $\begin{array}{c}\text { Detemine the } \\
\text { orgarisation } \\
\text { type }\end{array}$ & $\begin{array}{l}\text { Determine the } \\
\text { Organisation } \\
\text { Culture }\end{array}$ & $\begin{array}{l}\text { Detemine the } \\
\text { Projed's } \\
\text { Leadership } \\
\text { charaderistics }\end{array}$ & $\begin{array}{l}\text { Determine the } \\
\text { Tectnica } \\
\text { Environmert }\end{array}$ & $\begin{array}{l}\text { Determine the } \\
\text { Yea of Project } \\
\text { Completion }\end{array}$ \\
\hline
\end{tabular}

Fig. 3. Proposed Software Effort Estimation Process

Various generic attributes such as personality traits, power relationship and behavior changes were observed. Figure 4 summarizes the common leadership and cultural factors we selected. Based on this figure, we elaborated an ontology for culture and leadership. The ontology establishes a common measurement protocol and provides a uniform interpretation of project parameters. Figure 5 shows the team culture ontology and Figure 6 shows the leadership ontology. The purpose of such an ontology is two-fold: (1) to guide explicitly the measurement process; and (2) to associate measurement scales with each parameter. In our survey, a 1-9 scale was used to accommodate the majority of respondents and their responses. This would also give the responses a true value of their significance. The values of the corresponding Team Culture variables are specified as: 1-3 (Low), 4-6 (Nominal), and 7-9 (High).

Six factors were used to measure leadership characteristics, whereas seven factors were used to characterize culture. For example, communication was measured based on team and leader communication skills.

"Timely" means respecting time and the individual understands the general perception of time (event or relationship). If it is $95 \%$ of the time, then the value is clearly high. Low means that the individual slacks or has frequent absences. Nominal is when the individual frequently comes late to work or to a meeting. Collaboration (impersonal relations) means the leader does not allow personal 


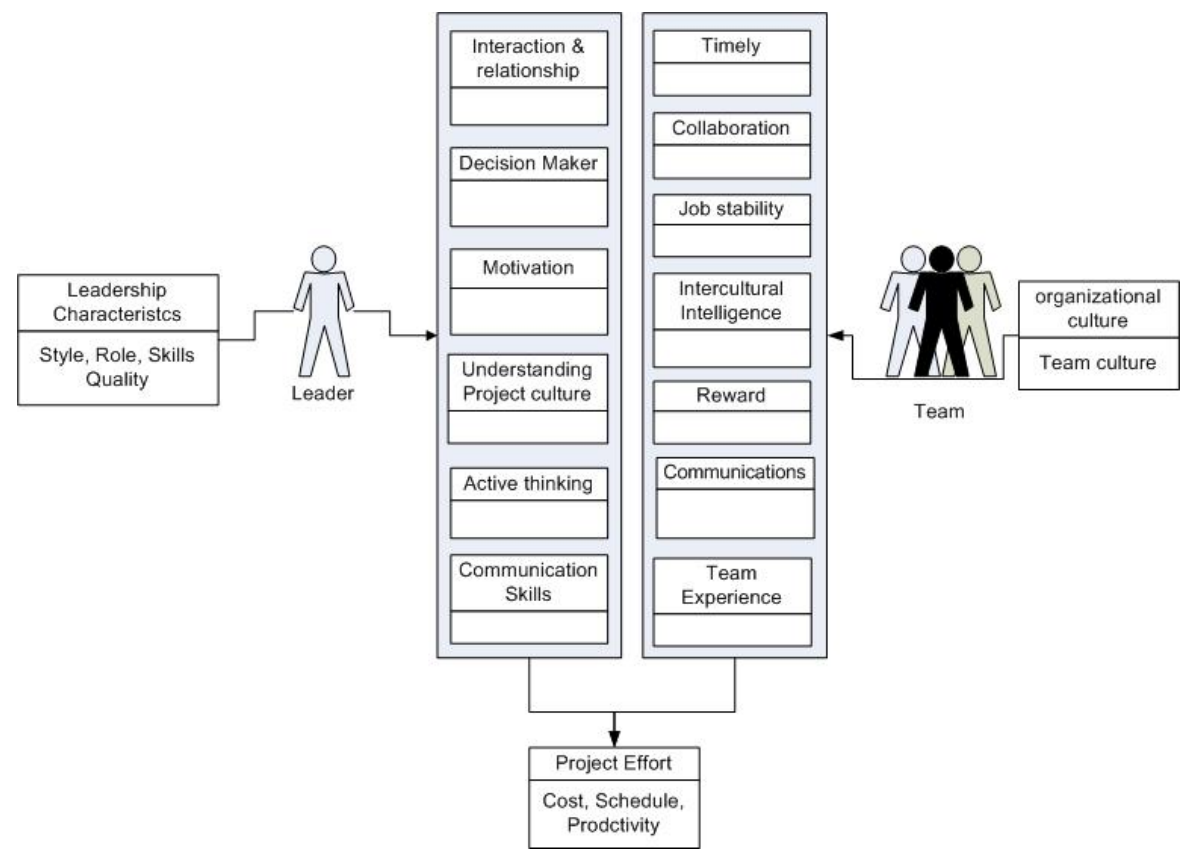

Fig. 4. Culture and Leadership Parameters

relationships to affect work. If this is $95 \%$ of time, then the value is high. Low means that the leader allows personal relationships to dominate work. Nominal is when the leader allows some personal relationships to affect work. Job stability means that the leader is a team player and holds no grudges against team members and his relationship is based on mutual trust and respect. If this is $95 \%$ of time, then the value is high. Low means that leader takes matters personally and has no trust. Nominal is when the leader holds some grudges against other members and teams. Intercultural Intelligence (impersonal relations) represents the ability to understand another culture's world view. If it is $95 \%$ of the time the leader understands others feelings, values, and goals and his ability to understand other culture world-views, and the value is high. Low means that the leader doesn't understand much about other people's feelings, values, and goals. Nominal means the leader is ignorant of other people's feelings, values, and purposes. Reward (Incentives) means the leader encourages and supports team professional development and rewards. If it is $95 \%$ of time, then the value is high. Low means the leader does not encourage or support team professional growth or rewards the team for achievements. Nominal means the leader provides some encouragement, supports the team's professional growth, and rewards some of the team's achievements.

Decision making means the leader encourages team members to communicate effectively. If it is $95 \%$ of the time, the team uses past experience to develop current or new projects and the value is high. Low means the leader doesn't 


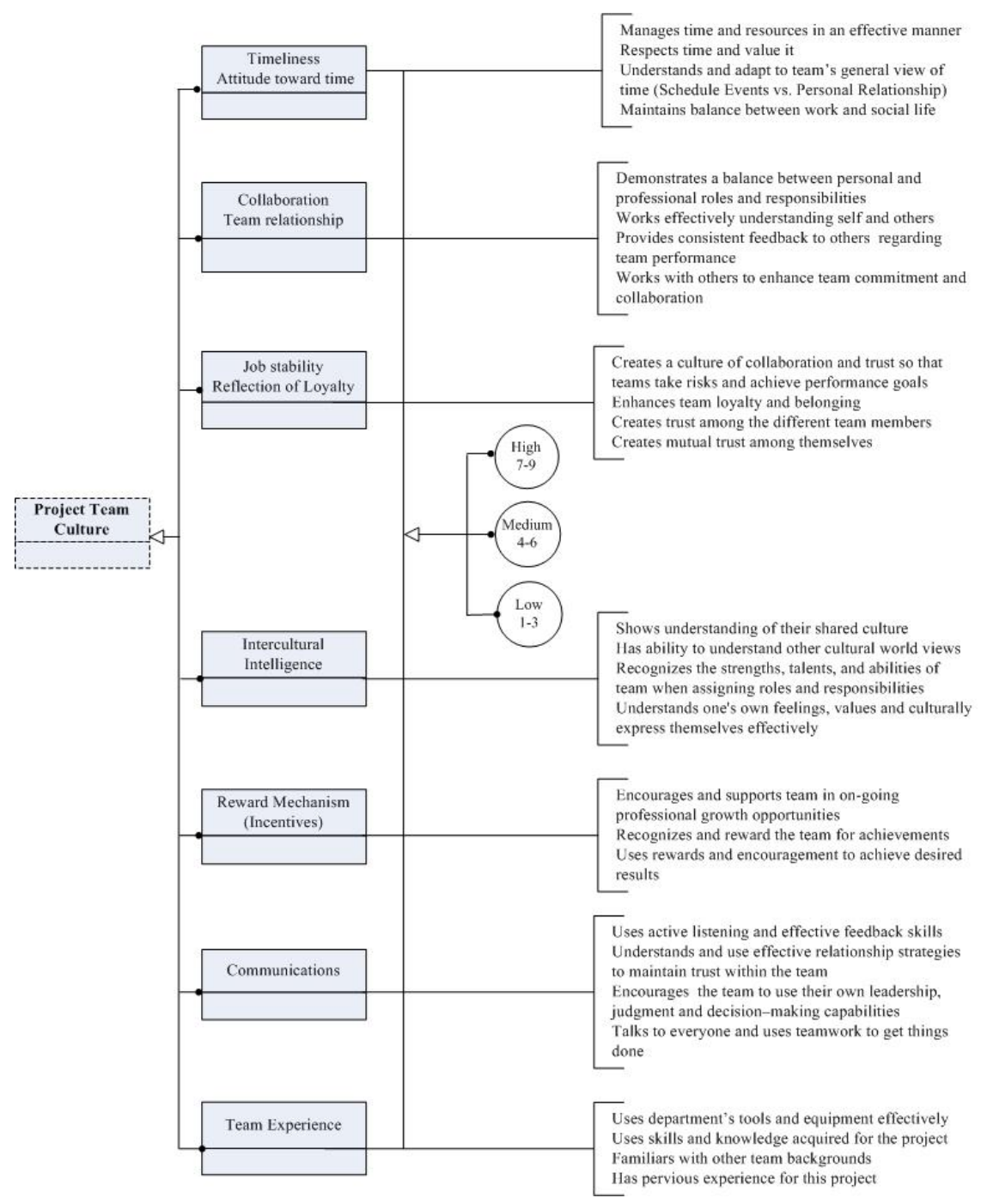

Fig. 5. Team Culture

allow any team members to use their own leadership, or decision making capabilities. Nominal means the leader allows some of team members to use their own leadership, decision making capabilities Team experience means the team works on similar projects and has the skills and knowledge. If it is $95 \%$ of time, then the value is high. Low means the team has never worked on similar projects nor skills or knowledge of the new project. Nominal means the team has worked on some similar projects and has some experiences and knowledge.

The leadership ontology categorizes several attributes (Fig. 6). Interaction (Behaviour) and relationship with team members means that the leader creates 


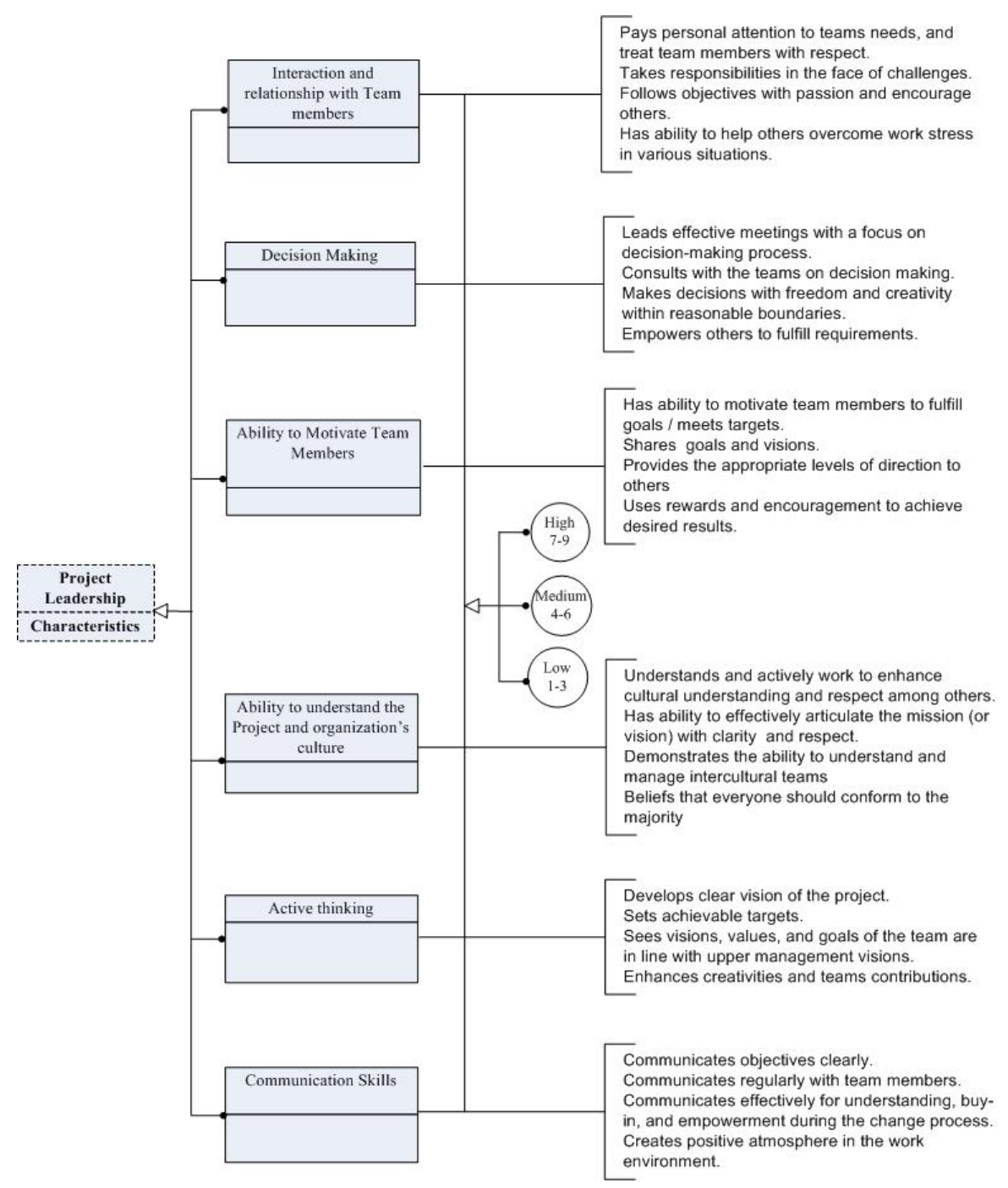

Fig. 6. Project Leadership

learning experiences, and treats team members with respect. If it is $95 \%$ of time, then the value is high. Low means the leader doesn't appreciate any of the team members' work. Nominal means the leader doesn't appreciate many of the team members' work. Decision Making of Leadership means the leader creates the right decisions and consults with teams about the organization's direction. Low means the leader doesn't make many proper decisions and doesn't react quickly to make decisions about the organization's problems. Nominal means the leader makes moderate decisions and consultations with teams and the reaction in making decisions to the organization's problems are slow or non-existent. The Ability 


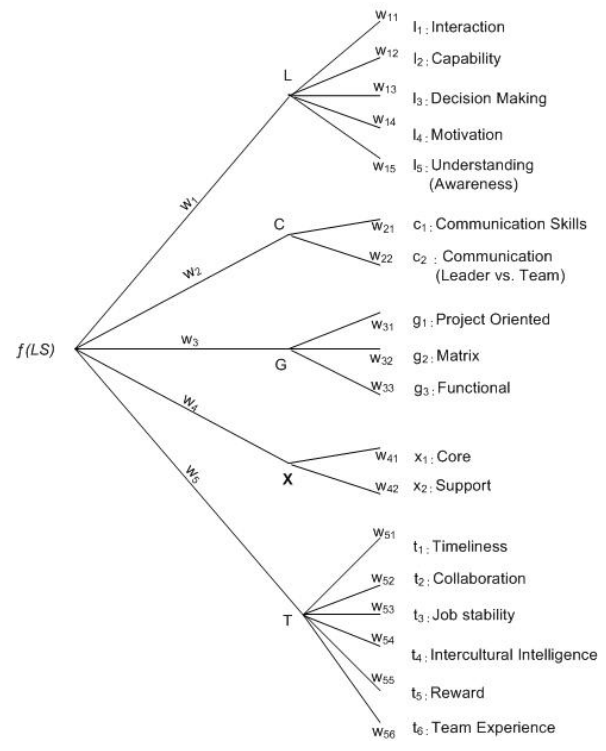

Fig. 7. Leadership factors tree

to Motivate Team members means that the leader shares goals and appropriate instructions and support. If it is $95 \%$ of time, then the value is high. Low means that the leader doesn't share many goals and appropriate levels of direction and support. Nominal means that the leader shares some of the goals with low encouragement to achieving and using some appropriate levels of direction and support are used.

The ability to understand the Project and the Organization's Culture means that the leader is able to understand and manage multicultural teams. If it is $95 \%$ of time, then the value is high. Low means that the leader doesn't have understanding of or management of intercultural teams. Nominal means that the leader has moderate understanding and managing intercultural teams. Active thinking means that the leader enhances team contributions and sets feasible target. If it is $95 \%$ of time, then the value is high. Low means that the leader doesn't enhance some of the team contributions. Nominal means that the leader has moderate enhancement, and medium team contributions feasible target. Communication Skills means that the leader uses communication among team members effectively. If Communicating regularly is $95 \%$ of time, then, the value is high. Low means communication is rare and has no effective feedback on team issues. Nominal means that the leader has some assisting and communication among team members.

Trying to combine leadership characteristics with other variables is difficult and involves quantitative measures of capability. The completeness property is important for the identification of the essential profile factors and for these to be incorporated into the profile description. One issue we are still addressing is how 
to use profile theory to describe leadership. For example, using the leadership factors tree (Fig. 7), we express the leadership $(L S)$ function as follows:

$$
f(L S)=\left\{\left(\epsilon_{1}, L, \omega_{1}\right),\left(\epsilon_{2}, T, \omega_{2},\left(\epsilon_{3}, G, \omega_{3}\right),\left(\epsilon_{4}, C, \omega_{4}\right),\left(\epsilon_{5}, X, \omega_{5}\right)\right\}\right.
$$

Where:

- L: Leadership characteristics, such as style, power, capability, traits, and skills

- T: Team characteristics, such as culture, knowledge, personal competencies

- $G$ : Organizational type, such as project-oriented, functional, or matrix authority

- $C$ : Communication skills, in both channels (leader vs. team culture)

- $X$ : Project complexity, such as core or support systems

$-\epsilon_{i}$ : Factor existence, such as $=1$, non existence $=0$; where is $\epsilon_{1}, \epsilon_{2}, \epsilon_{3}$, $\epsilon_{4}$, and $\epsilon_{5}$ are the factor existence for leader characteristics, team culture, organizational type, communication skills, and complexity, respectively.

- $\omega_{i}$ : Total weight of sub-factor(s) weight is divided equally in approximation ad hoc cases or based on importance or priority, where $\omega_{1}, \omega_{2}, \omega_{3}, \omega_{4}$, and $\omega_{5}$, are the weights for leadership characteristics, team culture, organizational type, communication skills and complexity, respectively.

\section{Implemented System}

We implemented a software tool, called SEEOS (Software Effort Estimation Ontology System) that supports the application of an analogy based method (Fig. 1 and Fig. 8). The tool provides a flexible interface that allows users to experiment with different project characteristic options. The main functions of SEEOS are the following: defining comprehensive attributes for a project, defining attributes characteristics and measurement protocol, providing choice of options to be considered such as culture factors and leadership, determining which attributes are available to provide better accuracy, and generating most similar projects for the required estimate. SEEOS consists of three subsystems: the analogy subsystem to find the most similar projects, the online subsystem used by different organizations to input projects data, and the bootstrap subsystem to validate the project result. Figure 8 shows the user interface of SEEOS. The left side panel shows the project's entities along with their attributes, descriptions and values. The right side panel shows the selected entities by the project manager(s) to be estimated. The model was tested on a number of governmental development projects in order to determine its accuracy and appropriateness. Experiment results were then analyzed. Our estimated results showed a good fit to actual data.

As the system was designed to provide an environment for testing the feasibility and validity of the proposed model, the developed version required further improvement. One issue that we faced was clustering. To be able to search for all possible feature subsets the system needs to cluster cases by business domain and complexity. Because the particular projects under investigation were from various domains and shared few projects, clustering was somehow difficult. For 


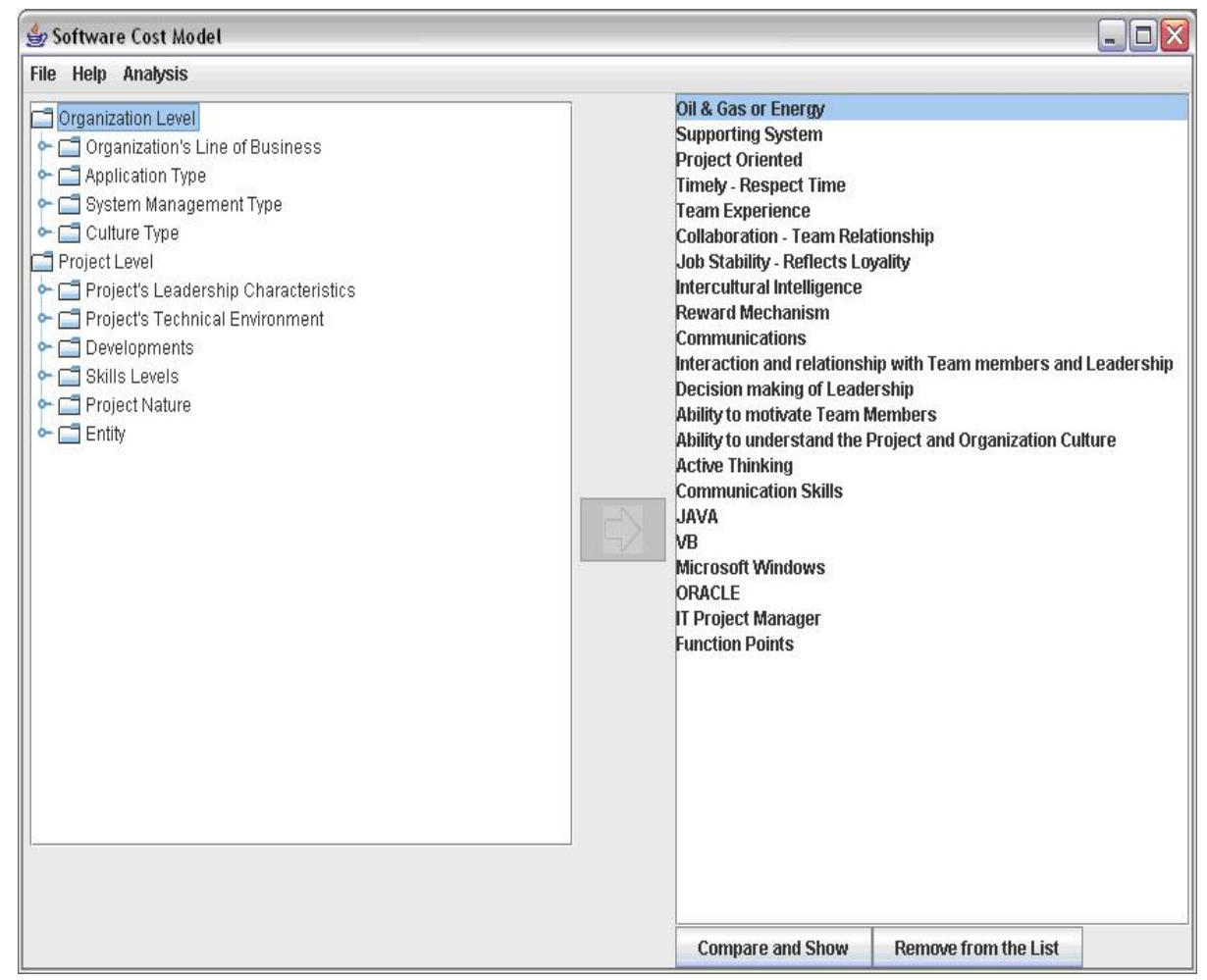

Fig. 8. SEEOS User Interface

example, it was difficult to measure the similarity of core systems in a different domain. A possible strategy would be to refine this notion of core systems by categorizing them according to application domains.

\section{Conclusion}

In the Gulf States, culture and leadership play a bigger role in affecting work performance. From the questionnaire and interviews, we concluded that software cost estimation in the Gulf often does not use accepted cost models. Due to the lack of a uniform protocol, variations in measurement cost among projects were noticed. To this effect, we categorized various factors affecting cost estimation and we developed an ontology to support an unambiguous interpretation of these factors. We also integrated culture and leadership in the CBR model. The inclusion of leadership and culture in the cost estimation model constitutes an enhancement and refinement. It also offers a possible enhancement to current models which do not take leadership and cultural backgrounds into account. In our research, two models, one with culture and one without culture have been used. Experiments to compare the effectiveness of these two models are still being carried out. 


\section{References}

1. Kitchenham, B., Pfleeger, S.L., Fenton, N.: Towards a Framework for Software Validation. IEEE Trans. on Software Engineering 21(12), 929-944 (1995)

2. Boehm, B.W.: Software Engineering Economics. Prentice-Hall, New Jersey (1981)

3. The Peace Corps Cross-Cultural Workbook, p. 10 (2008)

4. Futrell, R., Shafer, D., Shafer, L.: Quality Software Project Management. Software Quality Institute (2002)

5. Hamdan, K., Abu Sitta, F., Moses, J., Smith, P.: An Investigation into the Gulf States Government Approaches to Software Development and Effort Estimation. In: BCS 10th International Software Quality Conference, pp. 111-126. BCS Press, London (2005)

6. Shepperd, M., Jorgensen, M.: A Systematic Review of Software Development Cost Estimation Studies. IEEE 33(1), 33-53 (2007)

7. Shepperd, M., Schofield, C.: Estimating Software Project Effort Using Analogies. IEEE 23(12), 736-743 (1997)

8. Angelis, S.: A Simulation Tool for Efficient Analogy Based Cost Estimation. Empirical Software Engineering 5, 35-68 (2000) 